\title{
Thiolactosides: Scaffolds for the Synthesis of Glycolipids in Animal Cells
}

\author{
Masako Mori, ${ }^{1}$ Maria Carmelita Z. Kasuya, ${ }^{2}$ Mamoru Mizuno, ${ }^{1}$ and Kenichi Hatanaka ${ }^{2}$ \\ ${ }^{1}$ Laboratory of Glyco-Organic Chemistry, The Noguchi Institute, 1-8-1 Kaga, Itabashi-ku, Tokyo 173-0004, Japan \\ ${ }^{2}$ Institute of Industrial Science, The University of Tokyo, 4-6-1 Komaba, Meguro-ku, Tokyo 153-8505, Japan \\ Correspondence should be addressed to Kenichi Hatanaka, hatanaka@iis.u-tokyo.ac.jp
}

Received 10 November 2010; Accepted 7 January 2011

Academic Editor: Yuan Chuan Lee

Copyright (c) 2011 Masako Mori et al. This is an open access article distributed under the Creative Commons Attribution License, which permits unrestricted use, distribution, and reproduction in any medium, provided the original work is properly cited.

\begin{abstract}
Various glycolipids were synthesized using thiolactosides as scaffolds for glycosylation in animal cells. The basic building blocks, $n$-dodecyl $\beta$-D-thiolactoside ( $\beta$-LacSC12) and $n$-dodecyl $\alpha$-D-thiolactoside ( $\alpha$-LacSC12), were chemically synthesized in 2 steps: glycosylation followed by deacylation. The thiolactosides were administered to animal cells in culture and served as substrates for cellular enzyme-catalyzed glycosylation. Incubation of mouse melanoma B16 cells in the presence of $\beta$-LacSC12 or $\alpha$-LacSC12 resulted in sialylation of the terminal galactose residue and gave a GM3-type ganglioside. Administration of $\beta$-Lac SC12 in MadinDarby canine kidney (MDCK) cells likewise gave a GM3-type ganglioside. On the other hand, introduction of $\beta$-LacSC12 in African green monkey kidney (Vero) cells gave Gb3- and Gb4-type glycolipids aside from GM3-type ganglioside. In the course of the study, significant changes in B16 cell morphology and elevated secretion of melanin were also observed.
\end{abstract}

\section{Introduction}

Sulfur-containing compounds are gaining wide attention due to their potential application in the pharmaceutical industry as carbohydrate-based therapeutics or diagnostic agents. Thioglycosides, in which the glycosidic oxygen has been replaced by sulfur, are valuable stable glycoside analogues. The S-analogues of natural glucosides are resistant to enzymatic hydrolysis and have been proven to be useful glycosidase inhibitors with potential as therapeutics [1]. For example, thioglycosides showed promising application in the control of hyperglycemia in patients with diabetes by inhibiting the sodium-D-glucose transporter (SGLT) expressed in Chinese hamster ovary (CHO) cells [2].

Suzuki and his coworkers reported that S-glycoside analogues of gangliosides possess inhibitory activity for the influenza virus sialidase [3]. Novel linear polymers bearing thiosialosides as pendant-type epitopes have also been reported as influenza neuraminidase inhibitors [4].

The priming of glycosphingolipid synthesis by lactosyl ceramide analogues having nondegradable thioglucosidic linkages inhibited the cell surface expression of endogenous GM3 in B16 cells [5]. The S-glycosides of gangliosides have also been reported as inhibitors of endoglycoceramidase, the enzyme that hydrolyzes the glycosidic linkage between the oligosaccharide and ceramide [6,7].

Thioglycosides are used as glycosyl donors in the synthesis of biologically important oligosaccharides. They are among the widely used glycosyl donors considering the ease of preparation and shelf stability. Thioglycosides are compatible with numerous protection and deprotection steps required in oligosaccharide synthesis [8]. Moreover, thioglycosides are orthogonal to several other synthetic reactions involving trichloroacetimidate and glycosyl fluoride methods [9]. Pentenyl thioglycosides are widely used as glycosyl donors for the preparation of complex oligosaccharides in good yield [10].

In this research, $n$-dodecyl $\beta$-D-thiolactoside $(\beta$ LacSC12) and $n$-dodecyl $\alpha$-D-thiolactoside ( $\alpha$-LacSC12) were chemically prepared as shown in Scheme 1 and administered into animal cells such as mouse melanoma B16 cells, Madin-Darby canine kidney (MDCK) cells, and African green monkey kidney (Vero) cells to serve as substrates for the production of glycolipid-like compounds via enzymecatalyzed glycosylation by animal cells in culture [11, 12] The thiolactosides have a lactose moiety that is bound 

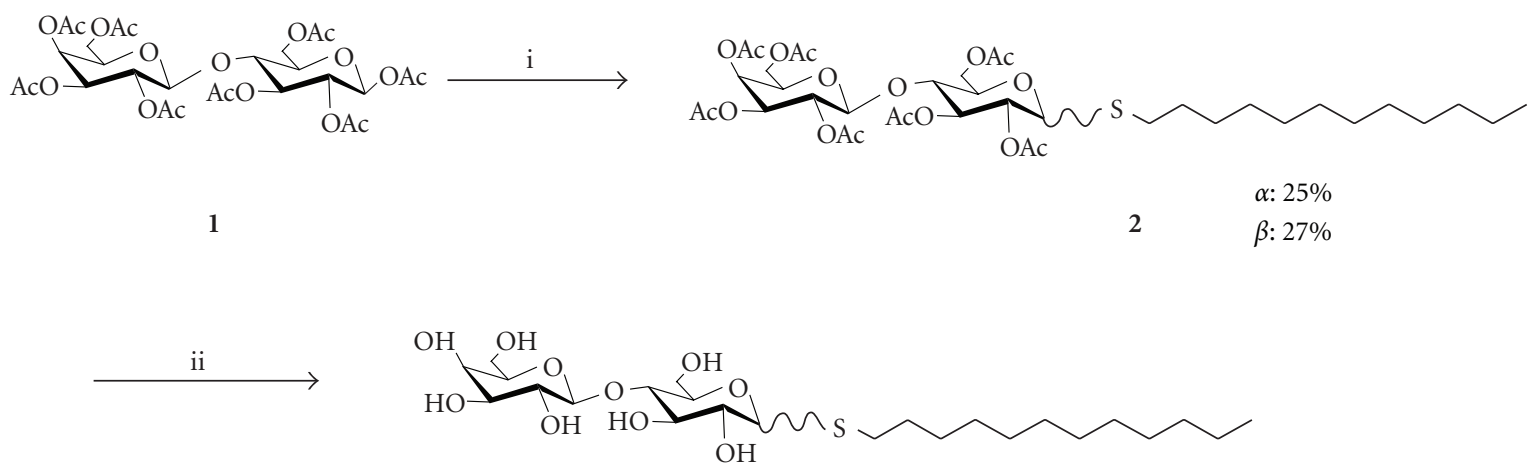

3

Scheme 1: Chemical synthesis of $n$-dodecyl $\alpha$ - and $\beta$-thiolactosides. Reaction conditions: (i) 1 -dodecanthiol, $\mathrm{BF}_{3} \cdot \mathrm{OEt}_{2}, \mathrm{CH}_{2} \mathrm{Cl}_{2}, \mathrm{r}$.t., overnight; (ii) $\mathrm{NaOMe}, \mathrm{MeOH}$, r.t., overnight.

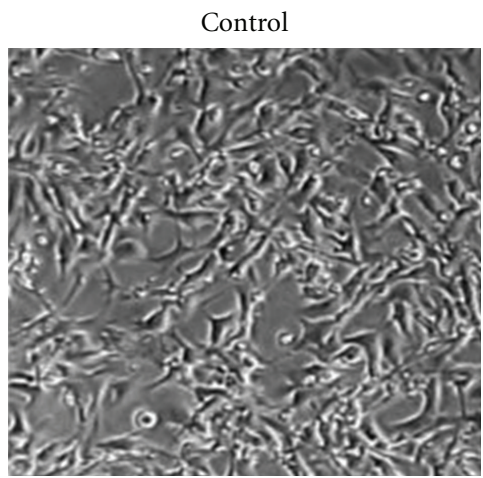

(a)

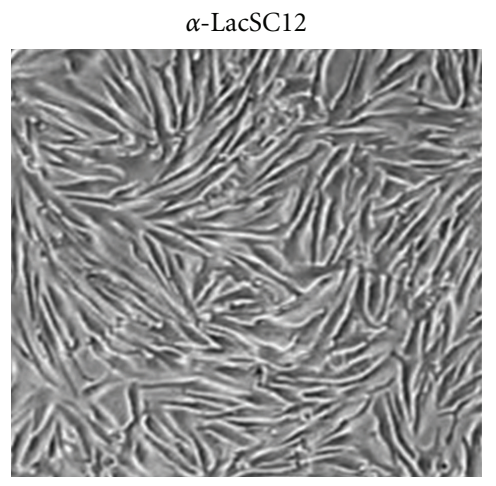

(b)

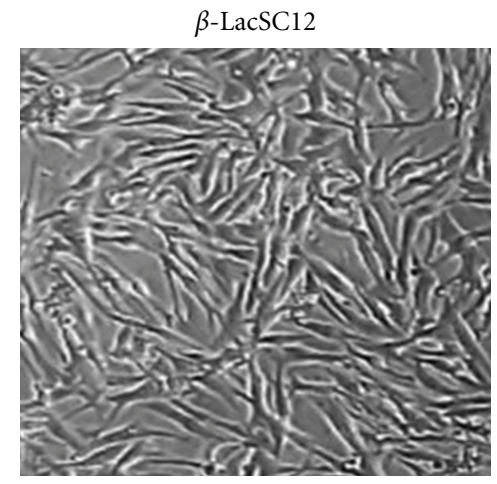

(c)

FIGURE 1: Effect on B16 cells after incubation in the absence (Control) and in the presence of $\alpha$ - or $\beta$-LacSC12. $2 \times 10^{6} \mathrm{~B} 16$ cells were seeded into $10 \mathrm{~cm}$ dishes containing $10 \mathrm{~mL}$ of $10 \%$ FBS DMEM/F12 and incubated for $72 \mathrm{~h} .50 \mu \mathrm{M}$ of each thiolactoside in $10 \mathrm{~mL}$ DMEM/F12 supplemented with insulin, transferrin, and selenium (ITS-X) was administered into cells.

through the anomeric carbon to the dodecyl aglycone via an S-glycoside bond. The hydrophobic aglycone would ensure assimilation into cells [13] and the appropriate chain length (C12) would allow release of the products to the culture medium. When administered to animal cell, the thiolactosides are expected to be glycosylated by enzymes and glycosyl donors inherent to the cells used [14-17].

\section{Experimental Method}

2.1. General Methods. ${ }^{1} \mathrm{H}$ and ${ }^{13} \mathrm{C}$ NMR spectra were recorded at a $600 \mathrm{MHz} \mathrm{JEOL}$ spectrometer in $\mathrm{Me}_{2} \mathrm{SO}-d_{6}$ or in $\mathrm{MeOH}-d_{3}$ or in $\mathrm{CDCl}_{3}$ using tetramethylsilane as internal reference. All reactions were monitored by thin layer chromatography (TLC) on Silica Gel 60 F-254 (Merck), with detection by UV light or by visualizing by spraying with anisaldehyde- $\mathrm{H}_{2} \mathrm{SO}_{4}$ and heating.

Dulbecco Modified Eagle's Medium (DMEM) and Ham F12 (1:1), trypsin, and insulin-transferrin-selenium (ITS$\mathrm{X})$ solution were from Gibco. The lactoside primers were dissolved in sterile $\mathrm{Me}_{2} \mathrm{SO}$ to an initial concentration of $50 \mathrm{mM}$. SepPak C18 was from Waters. HPTLC plates were from E. Merck, Darmstadt, Germany. $\mathrm{CHCl}_{3}: \mathrm{MeOH}: 0.25 \%$ $\operatorname{KCl}(\mathrm{aq})=5: 4: 1(\mathrm{v} / \mathrm{v} / \mathrm{v})$ was used as developing solvent for HPTLC. HPTLC plates were sprayed with resorcinol and heated to detect the separated glycolipids. The mass spectrum was recorded on a Bruker Esquire HCT Ultra ESI LC MS using $\mathrm{MeOH}$ : acetonitrile $(1: 1, \mathrm{v} / \mathrm{v})$.

2.2. Chemical Synthesis of Thiolactoside Primers. To a solution of $\beta$-peracetyllactose $(5 \mathrm{~g})$ in $100 \mathrm{~mL}$ dichloromethane was added 1-dodecanthiol (2 eq) and $\mathrm{BF}_{3} \cdot \mathrm{Et}_{2} \mathrm{O}$ (1.5 eq), and the mixture was stirred overnight at room temperature under argon. The reaction was stopped by the addition of saturated sodium bicarbonate. The $\alpha: \beta$ mixture of glycosylation product was separated by silica gel column chromatography (toluene: ethyl acetate, $3: 1$ ) and afforded $1.5 \mathrm{~g}(25 \%)$ and $1.7 \mathrm{~g}(27 \%)$ of the $\alpha$ - and $\beta$-glycosylation products, respectively. Deacylation was carried out by dissolving each glycosylation product in $100 \mathrm{~mL}$ methanol, and to the solution was added 1.05 eq of sodium methoxide. The mixture was stirred overnight at room temperature and then neutralized with cation-exchange resin (Amberlite, IR-120 $\mathrm{H}^{+}$form), filtered and evaporated. Recrystallization 


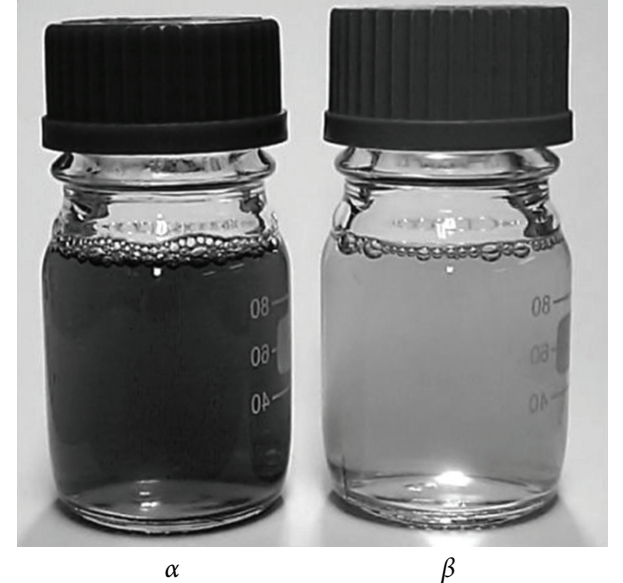

FIgURE 2: Culture medium collected after 48-hour incubation of B16 cells in the presence of $\alpha$ - or $\beta$-LacSC12.

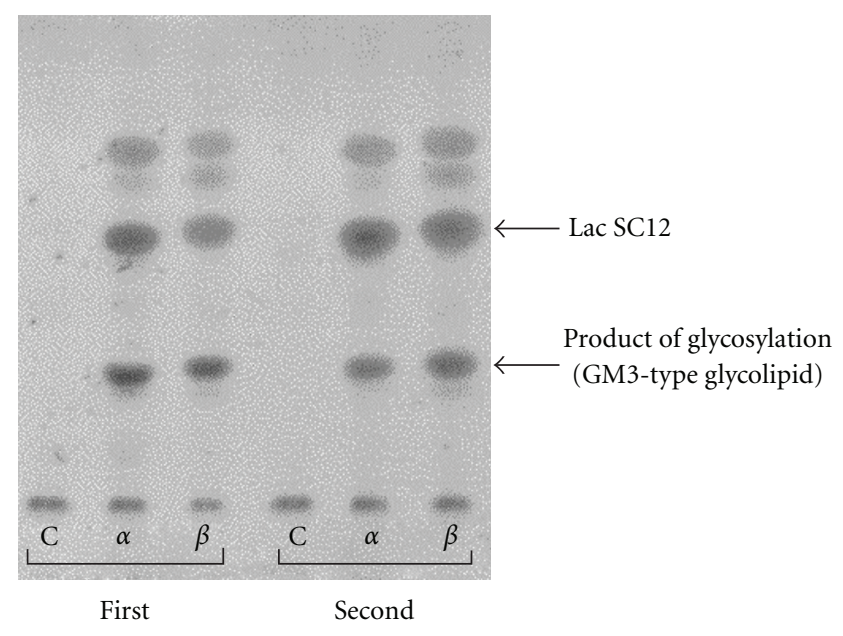

FIgURE 3: HPTLC profile of lipids from the culture medium fraction obtained after incubation of B16 cells in the absence of thiolactosides (C) and in the presence of the $\alpha$ - or $\beta$-LacSC12 (first and second harvests, 72 and $96 \mathrm{~h}$, resp.).

by warming at $45^{\circ} \mathrm{C}$ in a small amount of methanol followed by cooling at $-20^{\circ} \mathrm{C}$ afforded the $n$-dodecyl $\alpha$-Dthiolactoside ( $\alpha$-LacSC12) and $n$-dodecyl $\beta$-D-thiolactoside $(\beta$-LacSC12). The structures of the thiolactosides were confirmed from the NMR results. ${ }^{1} \mathrm{H}$ NMR $(\mathrm{AcO})_{7} \mathrm{Lac}-$ $\mathrm{SC} 12\left(\mathrm{CDCl}_{3}\right): \delta 0.87\left(\mathrm{t}, 3 \mathrm{H}, \mathrm{SCH}_{2}\left(\mathrm{CH}_{2}\right)_{10} \mathrm{CH}_{3}\right), 1.23-$ $1.37\left(\mathrm{~m}, 18 \mathrm{H}, \mathrm{SCH}_{2} \mathrm{CH}_{2}\left(\mathrm{CH}_{2}\right)_{9} \mathrm{CH}_{3}\right), 1.53-1.61(\mathrm{~m}, 2 \mathrm{H}$, $\left.\mathrm{SCH}_{2} \mathrm{CH}_{2}\left(\mathrm{CH}_{2}\right)_{9} \mathrm{CH}_{3}\right), 1.97-2.15(\mathrm{~m}, 21 \mathrm{H}, \mathrm{Ac}), 2.59-2.68$ $\left(\mathrm{m}, 2 \mathrm{H}, \mathrm{SCH}_{2}\left(\mathrm{CH}_{2}\right)_{10} \mathrm{CH}_{3}\right), 3.61$ (ddd, $\left.1 \mathrm{H}, \mathrm{H}-5\right), 3.78$ (dd, $\left.1 \mathrm{H}, J_{3,4}=9.6 \mathrm{~Hz}, \mathrm{H}-4\right), 3.86\left(\mathrm{ddd}, 1 \mathrm{H}, \mathrm{H}-5^{\prime}\right), 4.07-4.18$ (m, 3H, H-6a, H-6a' ${ }^{\prime}$ H6b'), 4.45-4.48 (m, 3H, H-1, H-1', H-6b), 4.91-4.96 (m, 2H, H-2, H-3'), $5.11\left(\mathrm{dd}, 1 \mathrm{H}, J_{1^{\prime} 2}=\right.$ $\left.8.3 \mathrm{~Hz}, J_{2^{\prime}}=10.3 \mathrm{~Hz}, \mathrm{H}-2^{\prime}\right), 5.21\left(\mathrm{dd}, 1 \mathrm{H}, J_{3,4}=9.6 \mathrm{~Hz}, \mathrm{H}-\right.$ 3), $5.35\left(\mathrm{dd}, 1 \mathrm{H}, \mathrm{H}-4^{\prime}\right)$.
2.3. Cell Culture and Administration of Thiolactosides. A $50 \mathrm{mM}$ stock solution of $\alpha$ - and $\beta$-LacSC12 primer was prepared by dissolving each thiolactoside in dimethylsulfoxide $\left(\mathrm{Me}_{2} \mathrm{SO}\right)$.

Mouse B16 melanoma cells $\left(2 \times 10^{6}\right.$ cells per $10 \mathrm{~cm}$ dish) were cultured in 10 mL 1:1 DMEM-F12 supplemented with $10 \%$ fetal bovine serum (FBS). When the cells were about $70 \%-80 \%$ confluent, the culture medium was changed to 1:1 DMEM-F12 (without FBS) containing $50 \mu \mathrm{M}$ of thiolactoside primer, and the cells were cultured for $72 \mathrm{~h}$. The culture medium was collected and cell culture continued for another $96 \mathrm{~h}$ in the presence of medium containing $50 \mu \mathrm{M}$ of thiolactoside. $50 \mu \mathrm{M}$ of $\beta$-LacSC12 primer was likewise administered to Madin-Darby canine kidney (MDCK) cells and into African green monkey kidney (VERO) cells which have been preincubated in the same culture medium under the same conditions.

Lipids from the culture media were purified using SepPak C18 column (Waters Cat. no. WAT020515) preconditioned with methanol. $2 \mathrm{~mL}$ of the collected medium was loaded to the column, washed with water and the desired products were eluted with $3 \mathrm{~mL}$ methanol. Evaporation of the eluent was accomplished using a centrifuge evaporator. Lipids from the culture medium fractions were analyzed by HPTLC with $\mathrm{CHCl}_{3}: \mathrm{MeOH}: 0.2 \%$ aq $\mathrm{KCl}(5: 4: 1, \mathrm{v} / \mathrm{v})$ as developing solvent. HPTLC plates were sprayed with resorcinol $\mathrm{HCl}$ reagent and heated for $10 \mathrm{~min}$ at $120^{\circ} \mathrm{C}$ in an oven to detect the glycolipids. The putative bands corresponding to glycosylated thiolactosides were analyzed to determine the structure of the products. The HPTLC plate was scanned, and the amount of elongated product was measured using SORBFIL TLC Video densitometer software.

Mass production of GM3-type oligosaccharide using $\beta$ LacSC12 was also carried out using B16 cell cultured in HYPER flask at a final concentration of $20 \mu \mathrm{M}$ for 3-5 days. Administration of thiolactoside and harvest of culture medium were repeated. To the collected medium was added the synthetic adsorbent Diaion HP20 to separate the product that was further purified using SepPak C18 (reversed phase) and InertSep SAX (anion exchange) cartridges.

\section{Results}

$n$-Dodecyl $\alpha$-D-thiolactoside ( $\alpha$-LacSC12) or $n$-dodecyl $\beta$ $D$-thiolactoside $(\beta$-LacSC12) was prepared in two steps: glycosylation of 1-thiododecyl alcohol using peracetyl lactose followed by deacylation under Zemplen conditions using sodium methoxide in methanol. The structures of the desired compounds were confirmed from both ${ }^{1} \mathrm{H}$ NMR and mass spectral results.

The purified thiolactosides were introduced to mouse melanoma B16 cells, Madin-Darby canine kidney (MDCK) cells, and African green monkey kidney (Vero) cells.

3.1. Effect on Cells. After 15 minutes from the addition of the thiolactoside primers, a remarkable change on B16 cell morphology was observed. Although B16 cells are epidermoid, the cells became elongated and acquired a slender shape 


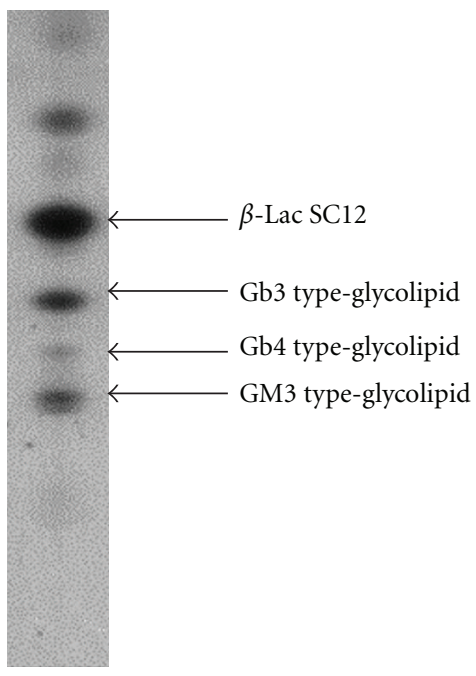

(a) Vero cells

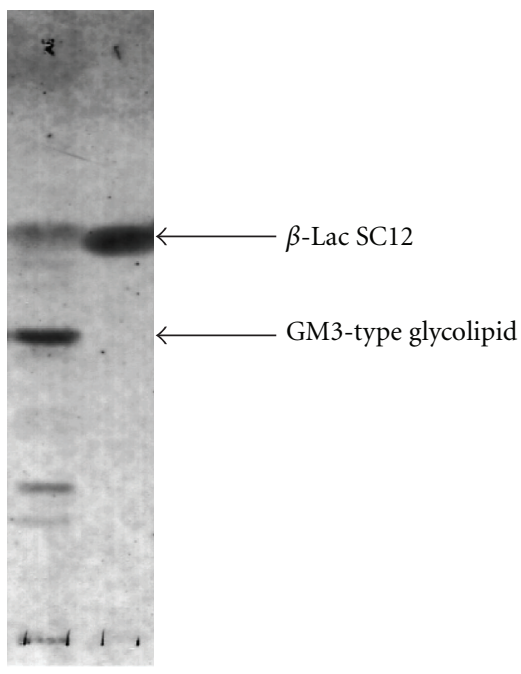

(b) MDCK cells

FIGURE 4: HPTLC profile of lipids from the culture medium fraction obtained after incubation of MDCK cells or Vero cells in the presence of the $\beta$-LacSC12.

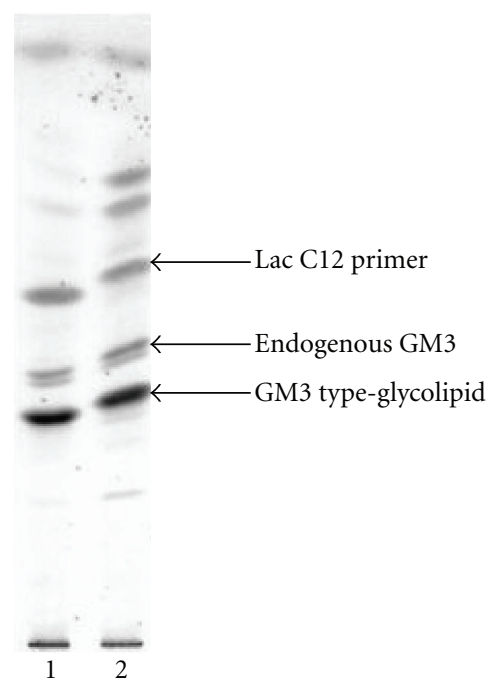

FIGURE 5: HPTLC profile of lipids from the culture medium fraction obtained after incubation of B16 cells in the presence of the $\beta$ LacOC12 (Lane 1) or $\beta$-LacSC12 (Lane 2).

similar to fibroblast cells as shown in Figure 1. In contrast, morphological changes were not observed in control cells that were incubated in the presence of $\mathrm{Me}_{2} \mathrm{SO}$ without thiolactoside. Any significant change in cell morphology was not observed when the thiolactoside was added to the culture media of MDCK cells and to Vero cells.

Cell proliferation of B16 cells was the fastest in the presence of $\alpha$-LacSC12 primer. No significant difference
TABle 1

\begin{tabular}{lc}
\hline Samples & Quant. on plate (ug) \\
\hline Alpha 1st & 3.06 \\
Beta 1st & 2.44 \\
Alpha 2nd & 2.02 \\
Beta 2nd & 2.83 \\
\hline
\end{tabular}

in proliferation was observed in the cells with $\beta$-LacSC12 primer.

As shown in Figure 2, melanin secretion increased as evidenced by the brown coloration of the culture medium collected from B16 cells incubated in the presence of $\alpha$ LacSC12 primer. Coloration of the culture medium was observed in the following order: $\alpha$-LacSC12 $>$ control $>\beta$ LacSC12.

3.2. Sugar Chain Elongation. HPTLC results confirmed the chain elongation of the thiolactoside primers as shown in Figure 3. Analysis of the bands corresponding to glycosylated thiolactosides by LC MS revealed that sialylation of the terminal galactose residue occurred and afforded a GM3type glycolipid ( $\mathrm{m} / \mathrm{z} 816.5$, negative mode shown in Figure 6) after incubation of mouse melanoma B16 cells in the presence of $\alpha$ - or $\beta$-Lac SC12 primers. An average of about $2.5 \mu \mathrm{g}$ of GM3-type product was obtained from $2 \mathrm{~mL}$ of the collected culture medium containing each thiolactoside (1.3 mg per liter of culture medium) as shown in Table 1.

On the other hand, incubation of Vero cells in the presence of $\beta$-LacSC12 gave GM3-type oligosaccharide along with Gb3-type and Gb4-type oligosaccharides as shown in Figure 4. The mass spectral result shown in Figure $6(\mathrm{~m} / \mathrm{z}$ 686.5, negative mode) confirmed the Gb3-type oligosaccharide. The fragmentation pattern of the mass spectrum obtained for the band between Gb3-type and GM3-type 

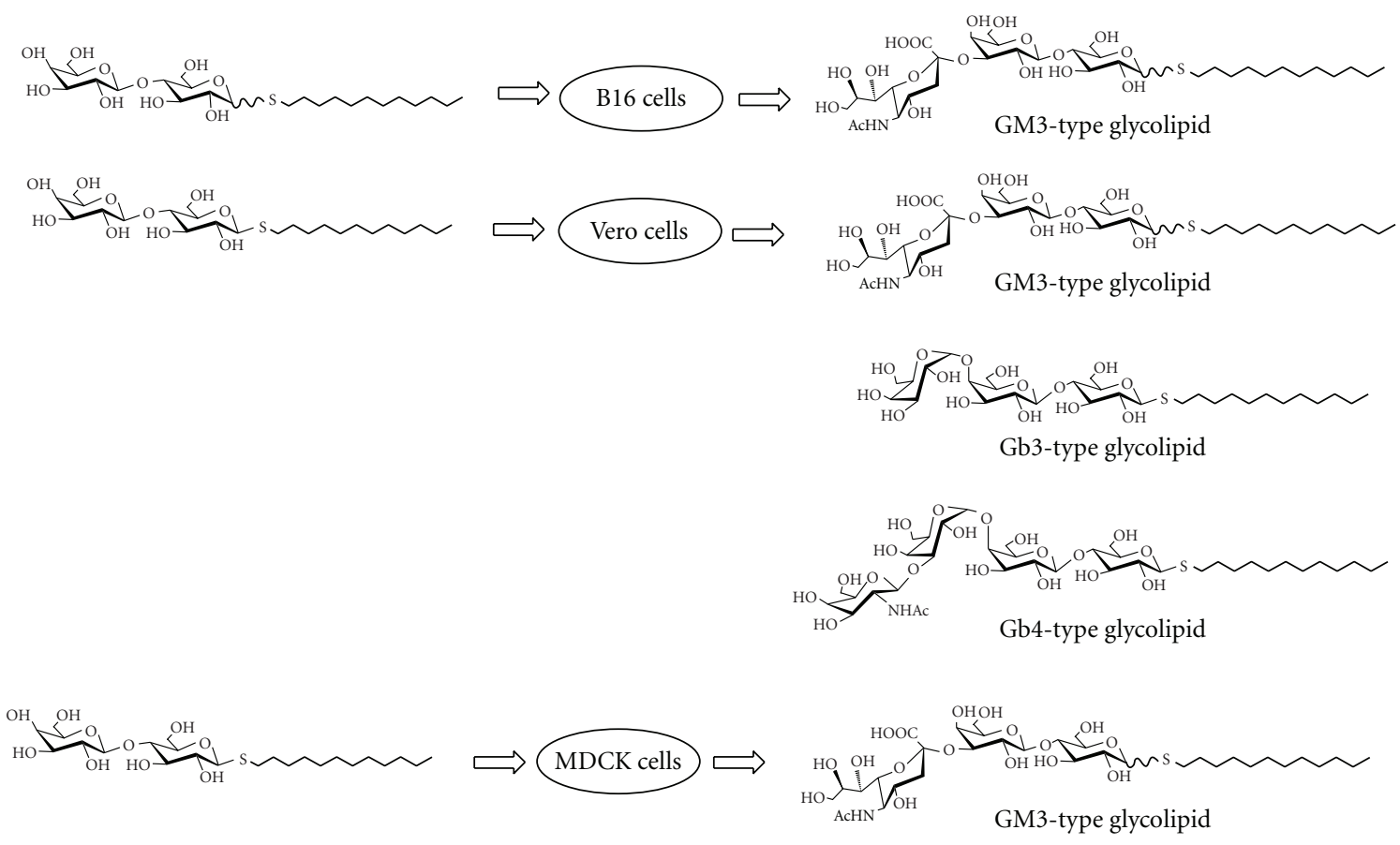

Scheme 2: Products of cellular enzyme-catalyzed glycosylation of thiolactoside.

oligosaccharides showed a peak corresponding to a GalNAc residue (data not shown). Based on the $\mathrm{Rf}$ value and the related literature [18], we could surmise that the band could be a Gb4-type oligosaccharide since, in Vero cells, Gb4 occurs naturally along with GM3 and Gb3 oligosaccharides.

Administration of $\beta$-LacSC12 into MDCK cells gave a GM3-type glycolipid as shown in Figure 4. The HPTLC results showed the presence of 2 more putative bands that could probably be GM1 and GM2-type glycolipid based on $\mathrm{Rf}$ values according to the literature. However, the amounts were too small to identify and quantify properly. Scheme 2 shows the products of glycosylation of the thiolactoside by the different cell lines used.

3.3. Comparison between $\beta$-LacSC12 and $\beta$-LacOC12. $n$ Dodecyl $\alpha$-D-lactoside $(\alpha$-LacOC12) with an O-glycosidic linkage was also prepared according to the literature [12] and added to the culture medium. $50 \mu \mathrm{M}$ of $\beta$-LacOC12 or $\beta$ LacSC12 was added to the medium of B16 cells for $120 \mathrm{~h}$. The respective lipids obtained from $1 \mathrm{~mL}$ of culture medium were used for HPTLC analysis and the amount of product quantified. As shown in Figure 5, the amount of product obtained from $\beta$-LacSC12 was slightly lower than the Oglycoside counterpart.

\section{Discussion}

Lactosyl ceramide is the common intermediate in glycolipid biosynthesis. An amphiphilic thiolactoside, an analogue of lactosyl ceramide, was examined in this study for the ability to prime glycolipid synthesis in various animal cells. Simpler in structure than the natural precursor, the thiolactoside employed has a lactose moiety linked to a hydrophobic dodecyl aglycone unit via S-glycosidic bond. The thiolactosides were chemically prepared and were obtained in fairly good yield via conventional methods of glycosylation using a Lewis acid as catalyst and deprotection under Zemplen conditions.

Incubation of cells for $72 \mathrm{~h}$ in the presence of the $\alpha$ - or $\beta$-LacSC12 resulted in glycosylation of the terminal galactose residue subsequent to cellular uptake. For elongation to take place, the thiolactosides were presumed to have diffused into the Golgi, the site of glycosylation. The chain length of the aglycone was significant to ensure not only the uptake but also the release of the products to the culture medium. HPTLC results confirmed that most of the products were found in the culture medium fraction.

Glycosylation was cellular specific. B16 cells gave GM3type ganglioside, the predominantly expressed glycolipid in the cell surface. MDCK cells also gave mainly GM3type glycolipid. On the other hand, African green monkey kidney (Vero) cells gave Gb3- and Gb4-type glycolipids aside from GM3-type ganglioside. The results also agree with a related work reported in the literature [18]. Based on these, we could infer that the thiolactosides entered the glycosphingolipid biosynthetic pathway and functioned as acceptors to afford products with saccharide structures similar to those produced by cells. By this strategy, various kinds of glycolipids could be conveniently prepared from various types of cells.

The $\alpha$-linked thiolactoside inflicted stress on the cells. This is evidenced by the elevated production of melanin, the pigment that gives color to protect the skin from the sunlight. As a natural response to the stimuli, the skin produces the pigment to protect from damage. In the case of B16 cells, increased production of the pigment was the visible response 


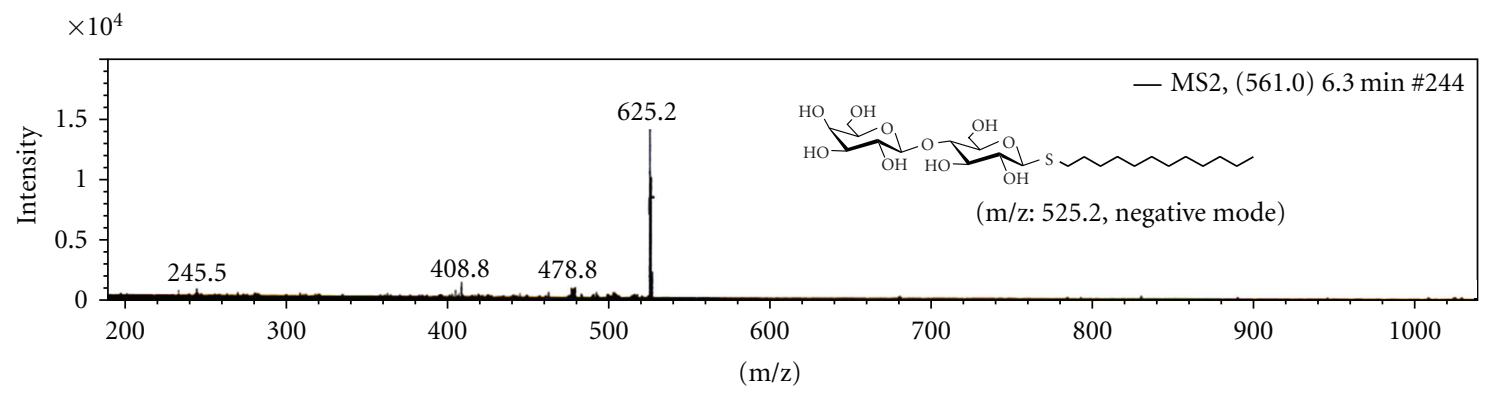

(a) Dodecyl thiolactoside

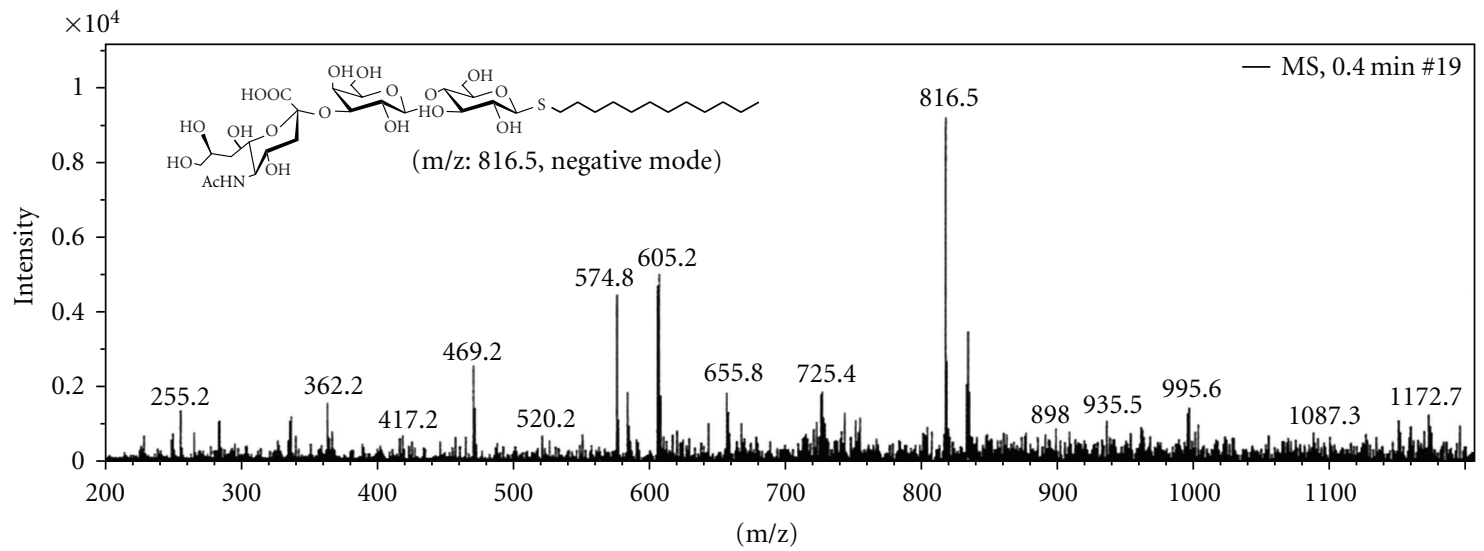

(b) GM3-type glycolipid

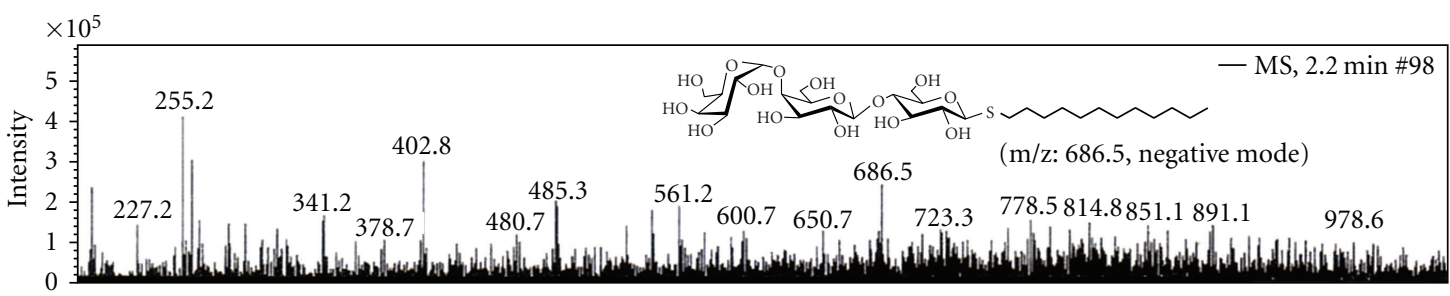

(c) Gb3-type glycolipid

FIgURE 6: Mass spectra of (a) dodecyl thiolactoside, (b) GM3-type glycolipid, and (c) Gb3-type glycolipid.

that protected the cells from adverse effects in the presence of the $\alpha$-linked thiolactoside. Interestingly, cells gave a different response in the presence of the $\beta$-linked thiolactosides as evidenced by the difference in color of the medium collected. The linkage between the saccharide and aglycone moieties has a significant effect on the pigment production by B16 cells.

According to the literature, S-glycosides are relatively stable and the lipid moiety is hardly affected by hydrolases (13). Although the natural biosynthetic process in the production of glycolipids involves O-glycosides, it was surmised that employing the $\alpha$-LacSC12 with a nondegradable thioglycosidic linkage to the aglycone would enhance the yield. However, the production of glycolipids using saccharide primers and cells showed otherwise. The amount of GM3type glycolipid produced using dodecyl thiolactoside was essentially the same or slightly lower when compared with dodecyl lactoside having an O-glycosidic linkage.
Mass production of GM3-type oligosaccharide using $\beta$ Lac SC12 was also accomplished by using B16 cell cultured in HYPERflasks at a concentration of $20 \mu \mathrm{M}$ of $\beta$-Lac SC12 for 3-5 days. After purification of the collected medium using SepPak C18 (reversed phase) and InertSep SAX (anion exchange) cartridges, $4.0 \mathrm{mg}$ of GM3-type oligosaccharide ( sialylated dodecyl thiolactoside) was obtained from 4.5 liters of culture medium (i.e., $0.9 \mathrm{mg} / \mathrm{L}$ of medium).

\section{Conclusion}

Various glycolipids could be obtained using thiolactosides and animal cells. Like the natural precursor with an $\mathrm{O}$ glycoside linkage, the thiolactosides could also be taken up by cells and glycosylated to afford glycolipids having the same saccharide structures as the cells produce. It is envisioned that incorporation of the thiolactosides in a variety of cells 
could generate a library of biologically important glycolipids. Glycolipids obtained by cellular glycosylation of thiolactosides could be further employed for the synthesis of more complex oligosaccharides. This strategy will even shorten the rather tedious preparation of oligosaccharides. Moreover, the glycolipids generated from thiolactosides have potential application as therapeutics by virtue of the presence of the sulfur atom.

\section{Acknowledgment}

This work was supported by a research grant from the New Energy and Industrial Technology Development Organization (NEDO).

\section{References}

[1] Z. J. Witczak and J. M. Culhane, "Thiosugars: new perspectives regarding availability and potential biochemical and medicinal applications," Applied Microbiology and Biotechnology, vol. 69, no. 3, pp. 237-244, 2005.

[2] F. Castaneda, A. Burse, W. Boland, and R. K. H. Kinne, "Thioglycosides as inhibitors of hSGLT1 and hSGLT2: potential therapeutic agents for the control of hyperglycemia in diabetes," International Journal of Medical Sciences, vol. 4, no. 3, pp. 131-139, 2007.

[3] Y. Suzuki, K. Sato, M. Kiso, and A. Hasegawa, "New ganglioside analogs that inhibit influenza virus sialidase," Glycoconjugate Journal, vol. 7, no. 4, pp. 349-356, 1990.

[4] K. Matsuoka, C. Takita, T. Koyama et al., "Novel linear polymers bearing thiosialosides as pendant-type epitopes for influenza neuraminidase inhibitors," Bioorganic and Medicinal Chemistry Letters, vol. 17, no. 14, pp. 3826-3830, 2007.

[5] Y. Miura and T. Yamagata, "Glycosylation of lactosylceramide analogs in animal cells: amphipathic disaccharide primers for glycosphingolipid synthesis," Biochemical and Biophysical Research Communications, vol. 241, no. 3, pp. 698-703, 1997.

[6] M. Ito and T. Yamagata, "A novel glycosphingolipid-degrading enzyme cleaves of the linkage between the oligosaccharide and ceramide of neutral and acidic glycosphingolipids," Journal of Biological Chemistry, vol. 261, no. 30, pp. 14278-14282, 1986.

[7] M. Ito and T. Yamagata, "Purification and characterization of glycosphingolipid-specific endoglycosidases (endoglycoceramidases) from a mutant strain of Rhodococcus sp. Evidence for three molecular species of endoglycoceramidase with different specificities," Journal of Biological Chemistry, vol. 264, no. 16, pp. 9510-9519, 1989.

[8] J. D. C. Codée, R. E. J. N. Litjens, L. J. Van Den Bos, H. S. Overkleeft, and G. A. Van Der Marel, "Thioglycosides in sequential glycosylation strategies," Chemical Society Reviews, vol. 34, no. 9, pp. 769-782, 2005.

[9] P. J. Garegg, "Thioglycosides as glycosyl donors in oligosaccharide synthesis," Advances in Carbohydrate Chemistry and Biochemistry, no. 52, pp. 179-205, 1997.

[10] J. Krag, M. S. Christiansen, J. G. Petersen, and H. H. Jensen, "Direct chemical glycosylation with pentenyl- and thioglycoside donors of N-acetylglucosamine," Carbohydrate Research, vol. 345, no. 7, pp. 872-879, 2010.

[11] M. C. Z. Kasuya, L. X. Wang, Y. C. Lee et al., "Azido glycoside primer: a versatile building block for the biocombinatorial synthesis of glycosphingolipid analogues," Carbohydrate Research, vol. 329, no. 4, pp. 755-763, 2000.
[12] M. C. Z. Kasuya, M. Ikeda, K. Hashimoto, T. Sato, and K. Hatanaka, "Effect of anomeric linkage on the sialylation of glycosides by cells," Journal of Carbohydrate Chemistry, vol. 24, no. 7, pp. 705-715, 2005.

[13] H. Nakajima, Y. Miura, and T. Yamagata, "Glycosylation of amphipathic lactoside primers with consequent inhibition of endogenous glycosphingolipid synthesis," Journal of Biochemistry, vol. 124, no. 1, pp. 148-156, 1998.

[14] A. K. Sarkar, J. R. Brown, and J. D. Esko, "Synthesis and glycan priming activity of acetylated disaccharides," Carbohydrate Research, vol. 329, no. 2, pp. 287-300, 2000.

[15] H. H. Freeze, D. Sampath, and A. Varki, " $\alpha$ - and $\beta$-xylosides alter glycolipid synthesis in human melanoma and Chinese hamster ovary cells," Journal of Biological Chemistry, vol. 268, no. 3, pp. 1618-1627, 1993.

[16] A. K. Sarkar, K. S. Rostand, R. K. Jain, K. L. Matta, and J. D. Esko, "Fucosylation of disaccharide precursors of sialyl Lewis ${ }^{\mathrm{X}}$ inhibit selectin-mediated cell adhesion," Journal of Biological Chemistry, vol. 272, no. 41, pp. 25608-25616, 1997.

[17] A. K. Sarkar, T. A. Fritz, W. H. Taylor, and J. D. Esko, "Disaccharide uptake and priming in animal cells: inhibition of sialyl Lewis $\mathrm{X}$ by acetylated $\mathrm{Ga} 1 \beta 1 \rightarrow 4 \mathrm{GlcNAc} \beta-O-$ naphthalenemethanol," Proceedings of the National Academy of Sciences of the United States of America, vol. 92, no. 8, pp. 33233327, 1995.

[18] A. Miyagawa, M. C. Z. Kasuya, and K. Hatanaka, "Alternative methods of globotrioside production using Vero cells: a microcarrier system procedure," Chemistry Central Journal, vol. 1, no. 1, article 26, 2007. 


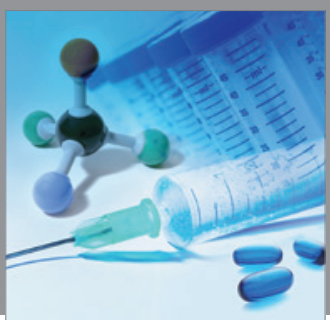

International Journal of

Medicinal Chemistry

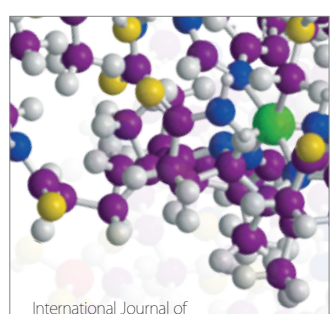

Carbohydrate Chemistry

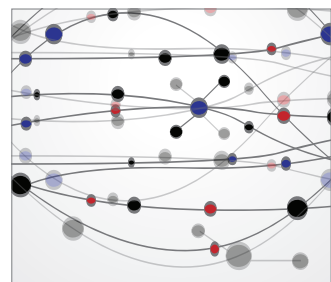

The Scientific World Journal
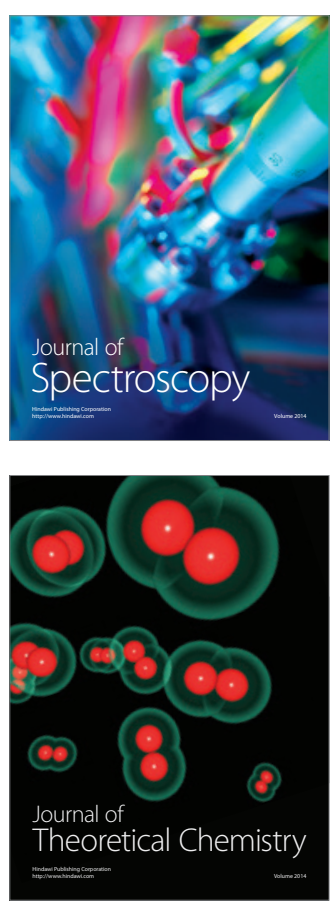
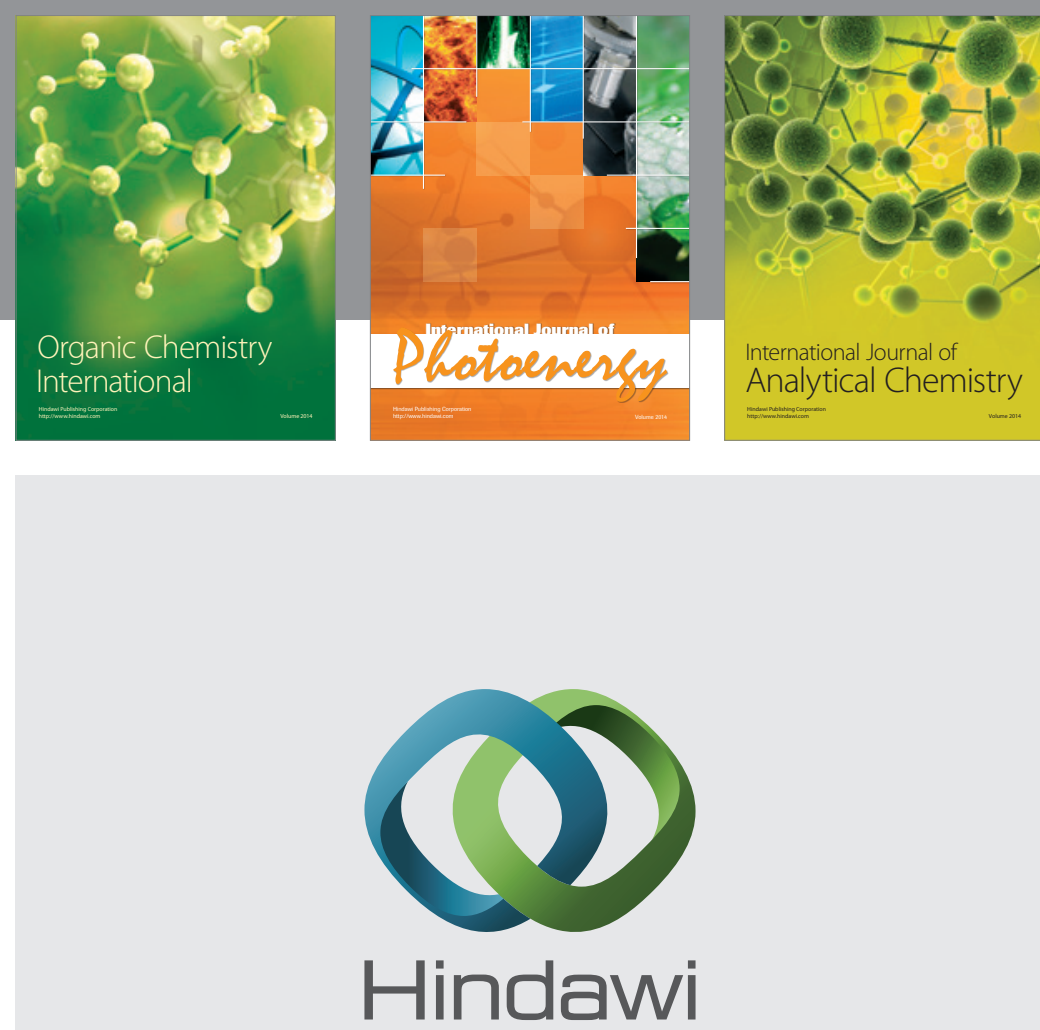

Submit your manuscripts at

http://www.hindawi.com
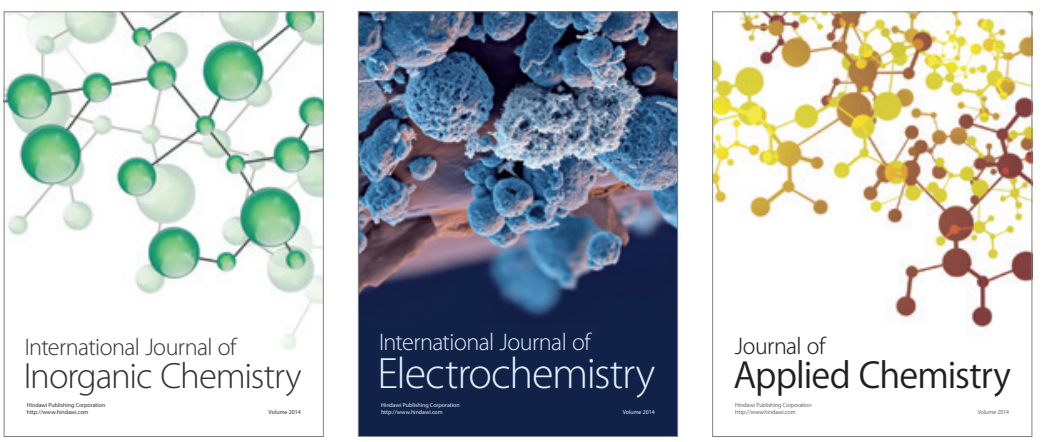

Journal of

Applied Chemistry
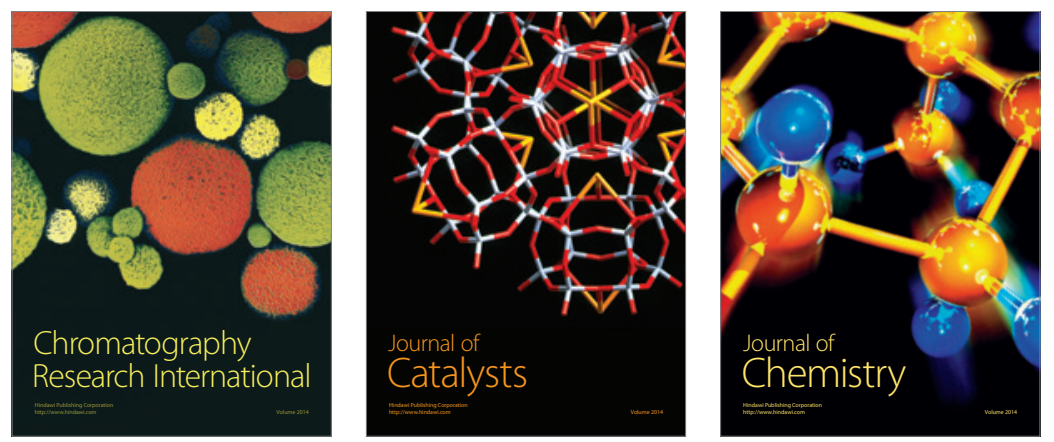
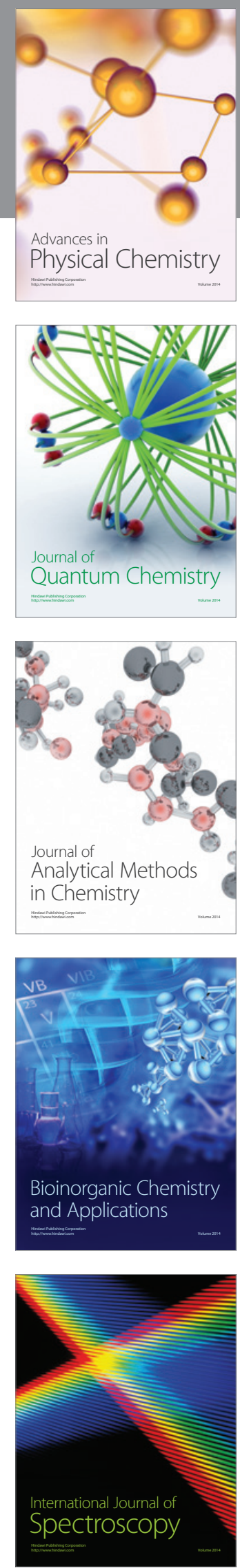